\title{
Deshilvanando imaginarios a través de fotografías de mujeres en Mar del Plata. La Prensa (Argentina, 1929-1934) ${ }^{1}$
}

\author{
Unraveling imaginaries through photographs of women in \\ Mar del Plata. La Prensa (Argentina, 1929-1934)
}

Susana Delgado

Universidad Nacional de Mar del Plata

DOI: https://doi.org/10.25032/crh.v7i12.7

Recibido: $31 / 3 / 2021$

Aceptado: $21 / 5 / 2021$

Resumen. Este trabajo tiene por objeto contribuir al análisis de la relación entre imagen e historia, desde el cruce entre los estudios visuales y los propios de género, a partir de la utilización de la fotografía de prensa como un artefacto, pero a la vez como una práctica social. Al entenderla como un mensaje que produce representaciones reconocemos a las fotografías como signos, como indicios de la realidad referenciada, a través de las cuales se construye un relato determinado del pasado. Por lo tanto, consideramos indispensable que los historiadores, apostemos a miradas interdisciplinarias al abordar las fotografías, como las de la sociología y la semiología. Dichas áreas nos previenen sobre la necesidad de proponer una lectura que deconstruya las formas de creencias que impregnan los imaginarios sociales, en cada momento histórico. Para ello apelamos al análisis de las condiciones históricas, sociales y culturales de la producción, distribución y recepción de los modos de representación tradicionales asociados a una estructura patriarcal. Nuestro abordaje, en este caso, se focaliza en el análisis de fotografías de mujeres del diario La Prensa, presentadas en un suplemento dominical sobre la temporada de verano en Mar del Plata, entre 1929 y 1934. En ellas se articulan formas de producción de sentido y modalidades de apropiación que organizan la cultura visual del período de estudio.

${ }^{1}$ Una primera versión de este texto corresponde al capítulo 2 de mi tesis de doctorado: $L a$ política de las fotografías, género y poder. Argentina 1930, UNMdP, 2015 
Palabras clave: Producción fotográfica, buen sentido, habitus, imaginarios

\begin{abstract}
This work aims to contribute to the analysis of the relationship between culture, image and history, at the crossroads between visual studies and the own gender based on the use of press photography as an artifact, but at the same time as a social practice. By understanding it as a message that produces representations, we recognize the photographs as signs, as indications of the referenced reality, through which a specific account of the past is constructed. Therefore, we consider it essential that historians bet on interdisciplinary views when approaching photographs, such as those of sociology and semiology. These areas warn us about the need to propose a reading that deconstructs the forms of beliefs that permeate social imaginaries, in each historical moment. For this we appeal to the analysis of the historical, social and cultural conditions of the production, distribution and reception of the traditional modes of representation associated with a patriarchal structure. Our approach, in this case, focuses on the analysis of photographs of women from the newspaper La Prensa, presented in a Sunday supplement about the summer season in Mar del Plata, between 1929 and 1934. In them forms of production of meaning are articulated. and appropriation modalities that organize the visual culture of the study period.
\end{abstract}

Keywords: Photographic production, good sense, habitus, imaginary

\title{
1. Introducción
}

En este trabajo pretendemos revisar cómo se hilvanan las tramas que conjugan determinados imaginarios, a través de fotografías de mujeres, desde un abordaje teórico que se ubica en la intersección entre los estudios visuales y los propios de género, en el marco de la vida turística veraniega, en Mar del Plata (Argentina) entre 1929 y 1934. La conexión de conceptos como patriarcadofeminidad-imagen-imaginación e imaginario, nos permite destejer una red configurada por la producción, circulación y consumo de un sistema de representación que organiza e instituye un imaginario social determinado. 
El objetivo es contribuir a la narrativa histórica incorporando otros lenguajes como objeto de análisis, con la finalidad de componer un relato que revisa la dimensión intertextual entre palabra e imagen y donde emerge con nitidez la construcción social de la diferenciación sexual y de clase. El terreno no es totalmente novedoso; lo que constituye un aporte, desde nuestra perspectiva, es la decodificación visual que desenmascara la imagen y la sitúa en una producción de sentido semiológico de carácter político.

El cruce teórico entre los estudios visuales y los de género propone la necesaria deconstrucción histórica dogmatizada por principios rectores antropocentristas al analizar las relaciones entre sexualidad, subjetividad y poder. No por cualidad las primeras producciones en este campo, durante los noventa, fueron desarrolladas por mujeres como las norteamericanas: Carol Duncan, Linda Nochlin, Lucy Lippard, en Estados Unidos y las británicas: Germaine Greer, Griselda Pollock y Rozsika Parker, entre otras. En la Argentina, la producción académica puso el eje en general en la conformación de la visualidad en términos de clase y género, en el marco de los procesos socioculturales: Laura Malosetti Costa y Marcela Gené (2009); Julia Ariza (2017); Sandra Szir (2007, 2009); Alejandra Niedermaier (2008); Georgina Gluzman (2019); Andrea Giunta (2018); mientras que desde una perspectiva más histórica, destacamos los trabajos con fotografías de Mirta Lobato (2005, 2008); Dora Barrancos y Ceppi (2005); Analía Rey y Cecilia Toussonian (2008); entre otros. Por último, en lo que refiere específicamente a Mar del Plata y las formas de representación social femenina fueron revisados por Graciela Zuppa (20042005, 2012) Gisela Kaczan (2010, 2012, 2014) y Gabriela Méndez (2012).

La propuesta metodológica incluye un análisis cuantitativo y cualitativo de un corpus fotográfico conformado por ciento ochenta y cinco rotograbados ubicados a doble página en sepia, en los suplementos del periódico La Prensa. La temática, en su mayoría, hace referencia a las actividades turísticas en las playas de Mar del Plata: La Perla, Bristol, de los Pescadores, de los Ingleses, Grande, Chica, Atlántico, Mogotes; las tardes con los paseos en carruajes, los juegos de tenis, de golf y de bridge, los concursos deportivos y los bailes nocturnos en los hoteles Bristol, Royal y el Ocean Club. 


\title{
2. El contexto histórico
}

Elisa Pastoriza es la autora de la tesis que periodiza la historia de la ciudad de Mar del Plata en tres etapas bien diferenciadas: la fundacional, referida al pueblo inicial de pescadores; el de la conformación de la ciudad de mar, para descanso de la elite, con una evidente impronta europea; y por último, como escenario de la democratización del bienestar, durante el, peronismo. Para la historiadora, la ciudad durante la década del treinta revestía características singulares:

\begin{abstract}
Aquellas transformaciones urbanísticas modernizadoras que anidaron el advenimiento de la luz eléctrica, las aguas corrientes, la difusión de las revistas y los periódicos, la fotografía y la cinematografía, una nueva estación ferroviaria y los grandes negocios y las tiendas. Tales cambios barren la ciudad con una ola de opulencia que llega a su apogeo con el denominado estilo Rambla Bristol, como dirá Victoria Ocampo a mediados de los treinta, en el que confluyen modelos de géneros modernistas y ciertas audacias estéticas (Pastoriza, 2009: 16).
\end{abstract}

Esta ola de opulencia de la ciudad, en el segundo período, fue impulsada por las familias más prominentes de Buenos Aires, con la finalidad de crear un espacio mundano, para el ocio, durante los meses de verano, conocido como la Biarritz argentina, durante la Primera Guerra Mundial. Los viajeros se trasladaban con el personal de servicio y permanecían de diciembre a marzo de cada año.

La fotografía acompañó a la vez que compuso estas relaciones a través de un estilo apropiado para ese grupo social, que exaltó pautas culturales, ritos y pasatiempos definidos por el deseo de distinción, el refinamiento y la exclusividad. Así, la vida cotidiana de las mujeres reproducía estrategias de práctica usual en Buenos Aires, cuyas representaciones destacaban su rol en la acción benéfica con una explícita subordinación patriarcal. ${ }^{2}$ En este contexto la feminidad de estas mujeres tenía características psíquicas, físicas y morales consideradas apropiadas, según su estado civil. El rol de las damas de la élite en

\footnotetext{
2 Patriarcado: En su sentido literal significa gobierno de los padres. Históricamente el término ha sido utilizado para designar un tipo de organización social en el que la autoridad la ejerce el varón jefe de familia, dueño del patrimonio, del que formaban parte los hijos, la esposa, los esclavos y los bienes. La familia es, claro está, una de las instituciones básicas de este orden social (Véase: Marta Fontenla, https://www.mujeresenred.net/spip.php?article1396)
} 
la cuestión social tuvo una larga trayectoria desde la creación de la Sociedad de Beneficencia de la Capital en 1823 por Rivadavia. 3

La visualidad de las vacaciones se fue democratizando hacia los sectores medios, que buscaban emular las prácticas de aquellos más distinguidos. Mercedes Monteverde, sobrina nieta del fotógrafo Mateo Bonin, y nieta de Manuel Suárez cuenta que hacia finales de 1900 Carlos Magnoni, Ulderico Carnaghi, Pedro Debenest, Montes de Oca, Mateo Bonin fueron algunos de los fotógrafos que se instalaron en la ciudad. A los que se sumaron los estudios en la Rambla Francesa, que tenían su sede central en Buenos Aires como Casa Witcomb, Freitas, Bixio, Mazer, mientras que en La Perla ya existían las casas: Aviador Cattaneo, Fotito, La Perla, Foto Suárez y otros (Monteverde, 2015).

Las fotografías realizadas a los veraneantes eran en muchos casos tomadas por sorpresa, estrategia de venta de los fotógrafos del lugar, porque al exhibirlas... en las vidrieras de sus locales de fotografía tentaban a más de un turista y/o fotografiado que pasaba por allí, a comprarlas, cuando sorprendidos se reconocían en ellas. Dichas postales con sus retratos eran enviadas con mensajes de salutación a sus seres queridos, dejando testimonio de su estadía en el balneario, además de llevarlas como recuerdo tras sus vacaciones, para atesorar esos momentos vividos durante toda su vida (Alexander, 2015: 10).

La circulación de las fotografías entre los sectores altos y medios se producía a través de los mismos fotógrafos que retrataban a la elite, quienes en muchos casos se alojaban en sus mansiones veraniegas y tomaban sol en el Ocean Club, jugaban en el Golf Club o bailaban en el Bristol Hotel. Del uso de la tecnología que proponían estos profesionales al sugerir poses, escenarios y telones de fondo adecuados para cada instancia iban trenzando las redes de una visualidad determinada. 4

\footnotetext{
3 La historiografía ha revisado la forma de organización de la asistencia a las niñas y mujeres por parte de las damas de la elite, como moralizadoras de la Nación (Ciafardo, 1990), su centralidad en la cuestión asistencial (Suriano, 1996, Moreno, 2000, Lobato, 1996, 2005, 2008; 1995-2007, 2008; Nash, 1991, Nari, 2000-2004); pero también al destacar los dones propios de su feminidad: humildad, dulzura, abnegación (Acha, 2000, Acha-Halperin, 2002, Tenti Fanfani, 1989, Delgado, 2011), y su vínculo permanente con el Episcopado argentino, cada vez que solicitaban autorización para la inserción de oratorios en sus estancias (Di Stéfano y Zanatta, 2000; Lida, 2005), y su preocupación por los métodos médicos aplicados, muchas veces en tensión con los higienistas (Pita, 2004, A. Alvarez, 2008, 2010).

4 Las fotografías que refieren a un baile de disfraces en febrero de 1934 en la mansión de María Unzué de Alvear son las únicas que llevan una leyenda que hacer referencia al fotógrafo: «Fotos Mazer».
} 


\section{El imaginario social}

La reiteración de estas representaciones, conformaron paulatinamente una iconicidad revestida de sentido al instalar un deber ser individual y colectivo en la sociedad. Cuando estas representaciones ubicadas en tiempo y espacio reflejan y comparten significaciones de cierta magnitud, podemos hablar de imaginario social (Agudello, 2011).

$\mathrm{El}$ abordaje de los imaginarios que se constituyen en diferentes momentos históricos nos permite percibir los valores que un grupo se instituye a sí mismo. $\mathrm{El}$ aporte en este punto radica en la posibilidad de investigar sus manifestaciones, sus producciones de sentido para advertir la excesiva configuración arbitraria que contiene.

La expresión imaginario social ha sido abordada por distintas disciplinas como la psicología social, la sociología, la teoría política, la filosofía, el psicoanálisis y la historia. Trabajamos aquí con el concepto que utiliza Cornelius Castoriadis (1993) por su contextualización ligada a lo sociohistórico y a su conexión con otras categorías teóricas como imagen, mentalidad e ideología. Entendemos que este fenómeno colectivo surge de un fluir denso y difuso que va configurando procesos de creación, a través de los cuales la sociedad inventa sus propios mundos y propone modos de ver que en forma paulatina instauran nuevos sentidos.

El imaginario social define a las sociedades humanas como creación ontológica de un modo de ser sui generis, absolutamente irreducible al de otros entes. Designa el mundo singular una y otra vez creado por una sociedad como su espacio propio. El imaginario social es un magma de significaciones imaginarias sociales (Castoriadis, 1993) encarnado en instituciones. Como tal, regula el decir y orienta la acción de los miembros de esa sociedad, en la que determina tanto las maneras de sentir y desear, como las maneras de pensar. En definitiva, ese mundo es esencialmente histórico. En efecto, toda sociedad contiene en sí misma una potencia de alteridad. Siempre existe según un doble modo: el modo de lo instituido, estabilización relativa de un conjunto de instituciones con sus producciones, y el modo de lo instituyente, la dinámica que 
impulsa su transformación. Por eso resulta conveniente hablar de lo socialhistórico. 5

Al deshilvanar los imaginarios propuestos en las fotografías seleccionadas del diario La Prensa hacia fines de la década del treinta, del siglo $\mathrm{xx}$, nos encontramos con una visión del mundo que establece determinados valores asociados a la feminidad de las mujeres de los más altos sectores. ${ }^{6}$ Los roles de las damas de la elite porteña que veraneaba en la ciudad balnearia son reiterados por el diario en los suplementos dominicales: el patrón maternal se descubre en las fotografías al cuidado de sus hijos en la playa, o frente a las mansiones de verano que ocupan, actividades de las que están exceptuadas las solteras quienes son retratadas solas o en grupos tomando sol en la playa o en los bailes de disfraces que se llevan a cabo en alguna de las mansiones; mientras que su rol social se despliega en las colectas y acciones benéficas hacia los distintos asilos existentes en la ciudad.

¿Cómo se llegan a instituir estos modos de homogeneizar comportamientos? Entendemos que el concepto de buen sentido de Roland Barthes, desde la semiología y el de habitus de Pierre Bourdieu, desde la sociología, pueden delimitarnos el camino.

\section{Las fuentes fotográficas}

En Argentina, los diarios La Prensa y La Nación fueron los primeros en incorporar la fotografía en sus ediciones, compitiendo así con la oferta visual que proponía la revista Caras y Caretas, desde su primer número en 1898. Ambos

\footnotetext{
5 Véase: Costoriadis, Cornelius, La institución imaginaria de la sociedad, Buenos Aires, Tusquets, 1993. Su obra parte del psicoanálisis freudiano y del marxismo; sin embargo los trasciende hasta el punto de proponer una teoría consistente que comprenda distintas dimensiones de la vida del hombre. Castoriadis habla de imaginario social, y entiende por social la institución que precede a la praxis y a la teoría. El imaginario social son variedades colectivas, puesto que lo imaginario no se da, sino en imaginarios locales, históricos y concretos. La idea de magma sugiere la relación indisoluble entre psique y sociedad.

6 Tomamos el concepto deshilvanar del artículo de Agudello, P. A. (Des)hilvanar el sentido/los juegos de Penélope. Una revisión del concepto de imaginario y sus implicaciones sociales. En: Uni-Pluri/versidad, Vol. 11- n. ${ }^{\circ}$ 3, Facultad de Educación, Universidad de Antioquía, Medellín, 2011. En su caso separa el prefijo haciendo eje en la tarea de tejer y destejer ligado a Penélope. La propuesta aquí estaría más ligada a la idea de deconstruir o mejor aún descomponer las partes de un todo naturalizado.
} 
periódicos funcionaban, desde lo ideológico político, como productores de bienes materiales de consumo efímero de fuerte simbolismo de clase.

Hacia mediados de la década del veinte del siglo Xx, estas publicaciones agregaron, en el suplemento de los domingos, las fotografías en rotograbados, 7 que presentaban una calidad superior a las que exhibía el mismo diario con otros procedimientos más rudimentarios. ${ }^{8}$ Estas imágenes se incluyen en la categoría general de fotoperiodismo - fotografías que forman parte de los medios de prensa- entre los productos culturales. La posibilidad de reproducir a través de la tecnología los sucesos ocurridos en todo el mundo promovió un rutilante desarrollo y transformación, paralelo a los avances en los sistemas de comunicación. 9

El diario La Prensa fue fundado el 18 de octubre de 1869 por José Clemente Paz, quien fuera ayudante de Bartolomé Mitre, en la batalla de Pavón. Unos meses después -en enero de 1870- este último crearía La Nación. Su lectura gravitaba con fuerza en la formación de opinión de sus lectores, hasta su expropiación por parte del gobierno, peronista, de acuerdo con la Ley 14.021 del 12 de abril de $1951 .^{10}$

\footnotetext{
7 El rotograbado es un sistema de impresión rotativo directo que emplea como porta imagen cilindros grabados en hueco, en forma de bajorrelieve. Dicha técnica fue suplantada por el offset.
}

${ }^{8}$ La aplicación de la fotografía a los medios gráficos no fue inmediata a su aparición. Recién hacia 1880, el New York Daily Graphic ilustró por primera vez sus páginas, con una fotografía realizada por Stephen Henry Horgan, con el título Shantytown (villa miseria). A partir de ese momento, los ilustradores iban a ser sustituidos por fotógrafos. El Daily Mirror comenzaría a utilizar la fotografía para ilustrar sus notas dieciséis años después. Por su parte en Argentina, la primera fotografía impresa apareció en La Ilustración Sud-americana en 1894, tres años después que Lillustration francesa publicara su primera fotografía en blanco y negro.(Tell, Verónica, «Reproducción fotográfica e impresión fotomecánica: materialidad y apropiación de imágenes a fines del siglo XIX», en: Malosetti Costa, Gené, Marcela, Impresiones porteñas, Imagen y palabra en la historia cultural de Buenos Aires, Buernos Aires, Edhasa, 2009)

9 Sobre el origen de fotografía de prensa ver: Freund, Gisele La fotografía como documento social, Barcelona: G. Gili, 2002; Benjamin, Walter, La obra de arte en la época de la reproductibilidad técnica, en: Sobre la fotografía, Valencia: Pretextos, 2005; Amar, Pierre-Jean El fotoperiodismo, Buenos Aires, La Marca, 2005; Baeza, Pepe, Por una función crítica de la fotografía de prensa, Barcelona: G. Gili, 2001. En Argentina: Malosetti Costa, Gené, Marcela, Impresiones porteñas, Imagen y palabra en la historia cultural de Buenos Aires, Buenos Aires, Edhasa, 2009; Rogers, Geraldine, Caras y Caretas, cultura, política y espectáculo en los inicios del siglo XX argentino, La Plata: UNLP, 2008.

${ }^{10}$ La expropiación se desencadena a partir de un conflicto gremial en el que muere un obrero del diario y catorce trabajadores resultan heridos. Los recortes presupuestarios de la empresa estaban ligados al problema fiscal vinculado con los derechos aduaneros del papel para diarios. Sin 
La Prensa fue uno de los diarios más importantes del país, por su tirada y por la influencia que sus notas y editoriales producían, tanto en los sectores de clase alta que se veían reflejados, como en aquellos que creían que, si las leían, accedían al mundo de los ricos distinguidos y respetables. Para estos otros, era una forma de espiar a los que tenían una vida que podía ser visibilizada en el espacio nacional.

En la hemeroteca del Archivo Histórico Roberto Barili de la ciudad de Mar del Plata se conservan varios libros contables usados como álbum de recortes que contienen páginas de sociales de la ciudad, durante el verano. Es una selección de notas que incluye casi exclusivamente representaciones de la vida turística del balneario. ${ }^{11}$ Estos libros/álbumes, tienen pegadas en su interior, páginas en sepia, del diario La Prensa, que datan de 1929 a 1934. Son folios dobles de mayor calidad de impresión, donde se conjugan la modernidad técnica y la producción simbólica. ${ }^{12}$

El corpus que organizamos cuenta con 185 fotografías sobre un total de 356 imágenes que hacen referencia a las actividades en las playas: La Perla, Bristol, de los Pescadores, de los Ingleses, Grande, Chica, Atlántico, Mogotes; las tardes con los paseos en carruajes, los juegos de tenis, de golf y de bridge, los concursos deportivos y los bailes nocturnos en los hoteles Bristol, Royal y el Ocean Club. Está clasificado en forma numérica, por títulos, en orden cronológico. Cada uno de los cuadros de la serie contiene, además, el número, las dimensiones, la ubicación en la página de cada fotografía y el epígrafe correspondiente. La selección está ligada fundamentalmente a la calidad de las imágenes.

embargo había además un ingrediente político fundamental. Junto con La Nación, La Prensa eran considerados por Perón como «diarios de la oposición en manos de la oligarquía argentina y pagos, en forma disimulada por los intereses foráneos» (Carta de Perón al senador chileno Arturo Alessandri 29-8-49). Véase: Baschetti, Roberto (2000) Clase en la Universidad Nacional de La Plata, Facultad de Periodismo y Comunicación Social; en el marco de la materia: «Una interrelación entre Periodismo e Historia Política Argentina».

${ }^{11}$ Entre el personal de la institución se dice que dicha recopilación de recortes fue hecha por el propio Barili, organizador del archivo

${ }^{12} \mathrm{El}$ corpus completo con el que trabajamos forma parte del segundo capítulo del libro

Fotopolítica. Historia y Memoria. Propuestas Metodológicas. Archivo de la Palabra e imagen, (Véase: https://archivopalabra.com.ar/items/show/79) 


\section{El buen sentido en las fotografías de La Prensa}

Los patrones culturales que organizan las imágenes se fueron forjando según los usos fotográficos más distinguidos de los centros de sociabilidad europeos. El concepto de Barthes del buen sentido, tiene que ver con esto. Y nos permite pensar la extraordinaria distancia que existe entre el modelo y la cámara -o, en términos semiológicos, entre el significante y el significado-, al momento en que el fotógrafo oprime el obturador, y nos alerta sobre la distancia que existe entre lo que se ve y lo que es, entre realidad y relato, entre naturaleza e historia. El semiólogo francés ${ }^{13}$ reflexiona sobre la fotografía, hacia mediados de los años cincuenta del siglo xx en los textos reunidos en Mitologías:

\section{Reclamo vivir plenamente la contradicción de mi tiempo, que puede hacer de un sarcasmo la condición de verdad [...] el «buen sentido» conceptualizado como una filosofía general de la humanidad, como una identidad que establece rápidamente una naturaleza, una equivalencia entre lo que se ve y lo que es (Barthes, 2005: 89).}

El escritor francés también se ocupa de la fotografía de prensa en $E l$ mensaje fotográfico, cuando la analiza como un mensaje constituido por una fuente emisora, un canal de transmisión y un medio receptor. La primera es la redacción del diario, el grupo de técnicos y reporteros, que sacan fotografías, las componen, las seleccionan y la jerarquizan en determinados espacios, le ponen un título y una leyenda. Tanto la emisión como la recepción se inscriben en los imaginarios que permean a la sociedad, a través de actitudes, móviles y comportamientos definidos. La estructura visual está acompañada por la estructura del texto lingüístico: la leyenda, el título, los resaltados, etcétera.

El buen sentido que proponía el diario La Prensa a sus lectores pasaba por las vacaciones estivales en la ciudad balnearia más importante del país. La misma elite consumidora del medio gráfico esperaba verse reflejada en La Prensa. Este interés impulsaba, ordenaba y organizaba la rutina veraniega, en consecuencia marcaba pautas de conducta esperadas para estas mujeres. El dueño del diario interactuaba en la ciudad balnearia con el grupo social al que representaba. Los integrantes de la familia Gainza Paz son mencionados en algunos epígrafes. La

${ }_{13}$ En el diario Le Monde, Barthes expresó en 1974 «La semiología se me apareció, entonces, por su porvenir, sus programas y sus tareas, como el método fundamental de la crítica ideológica». Hacía referencia a su obra Mitologías, desde donde pretendía denunciar los mitos pequeñoburgueses, desde un análisis de los procesos de sentido, a través de los cuales, la burguesía convierte su cultura histórica de clase, en cultura universal. 
mayoría de las imágenes se inscribe geográficamente en la playa. La moda de las jóvenes, las actividades de ocio desarrolladas, así como sus hijos y lugares de residencia, creaban modas y tendencias sobre cómo disfrutar en el período estival, cada año, en Mar del Plata. Para los dueños del diario constituía la reafirmación de su participación y compromiso en la conformación de un espacio propio de pertenencia y distinción social. Por su parte, desde una perspectiva de género, el buen sentido exhibía a las mujeres frente al volante o en tertulias femeninas solo en ocasión de realizar alguna actividad benéfica, tal es el caso de la fotografía de las jóvenes que recolectaban dinero a beneficio de los niños del puerto, con motivo del Día del Pescador, en los espacios de playa (Fig. 1) o de Mercedes Alvear, que ocupa el volante - tarea netamente masculina- porque así lo amerita la actividad a beneficio del colegio religioso Stella Maris (Fig. 2).

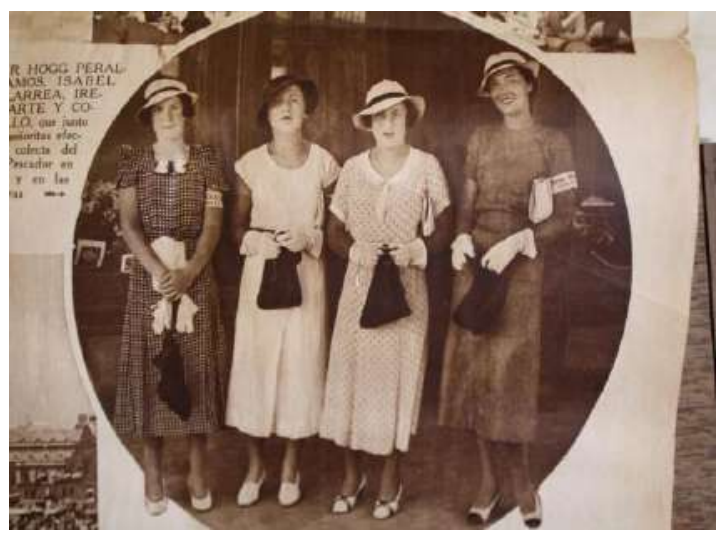

Imagen 1. Libro 5 , Foto $n .^{\circ} 105,1 .^{\circ}$ de febrero de 1933. Esther Hogg Peralta Ramos, Isabel Uribelarrea, Irene Ugarte, y Cora Gallo, que junto con otras señoritas efectuaron la colecta del Día del Pescador en la rambla y en las playas.

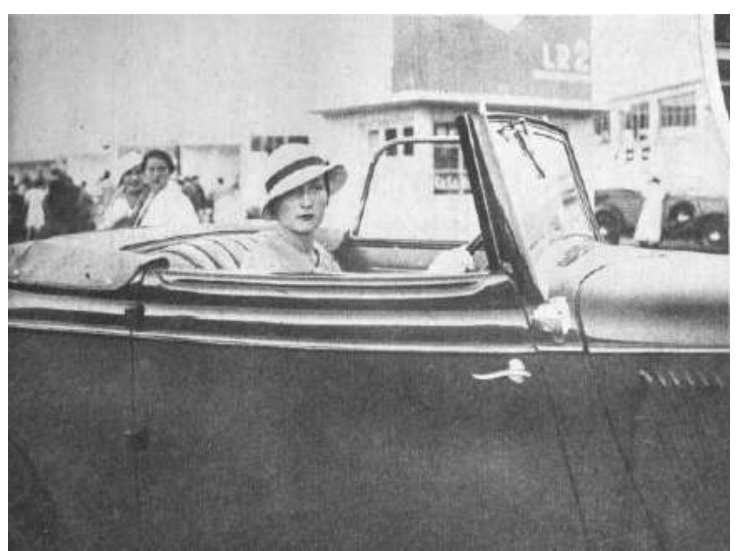

Imagen 2. Libro 5 , Foto n. ${ }^{\circ} 128,18$ de febrero de 1934. Mercedes Alvear que obtuvo uno de los premios de conjunto en el concurso automovilístico a beneficio de Stella Maris.

El buen sentido, además, selecciona y recorta el tema del verano en Mar del Plata con el objeto de difundir y reproducir símbolos de clase y de género, por ejemplo, al registrar los juegos de los niños en la playa, o sus atuendos veraniegos como gorros y salidas de baño. Para ello, los epígrafes que acompañan las imágenes cumplen una función muy precisa al distinguir con nombre y apellido a cada uno. 


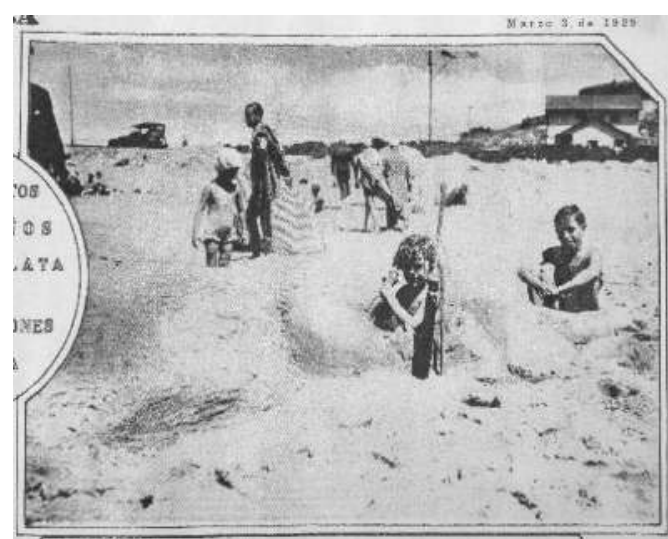

Imagen 3. Libro 1 , Foto $n .^{\circ} 2,3$ de marzo de 1929. Julio César Genoud y Jorge Berardi

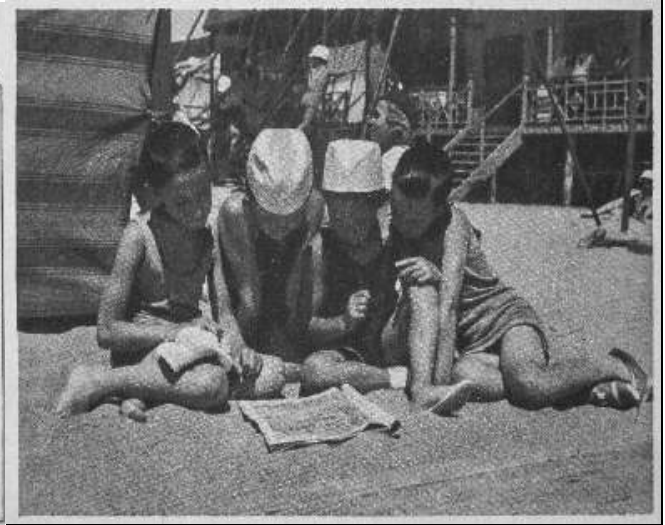

Imagen 4. Libro 5 , Foto $\mathrm{n} .^{0} 106,11$ de febrero de 1934. Roberto y José A. Fresco y José M. y Alberto White

En cuanto a las mujeres, su nivel social les permite que sean representadas como modelos, en algunos casos con los piyamas de moda de la última temporada, como vemos en las imágenes del 3 de marzo de 1932, con el título La moda de los piyamas en las playas de Mar del Plata, donde se presentan 11 fotografías. Los epígrafes correspondientes las destacan con nombre y apellido, seguidos de las características del modelo que llevan puesto, por ejemplo:

- Enriqueta Pradere Castex de Gainza Paz, piyama de seda blanca y saco floreado en rubí, Sofía Cranwell de Demarchi, en azul, Martha Bosch Alvear de Estrada, piyama azul y blusa celeste; Delia Carmen Ocampo Alvear en crepe de chine color oro con lunares azules (Foto n. ${ }^{\circ} 54$ )

- Magdalena Bullrich de sarga azul y malla rayada azul y blanca; Magdalena Uribelarrea, de brin blanco (Foto N. ${ }^{\circ} 5$ ).

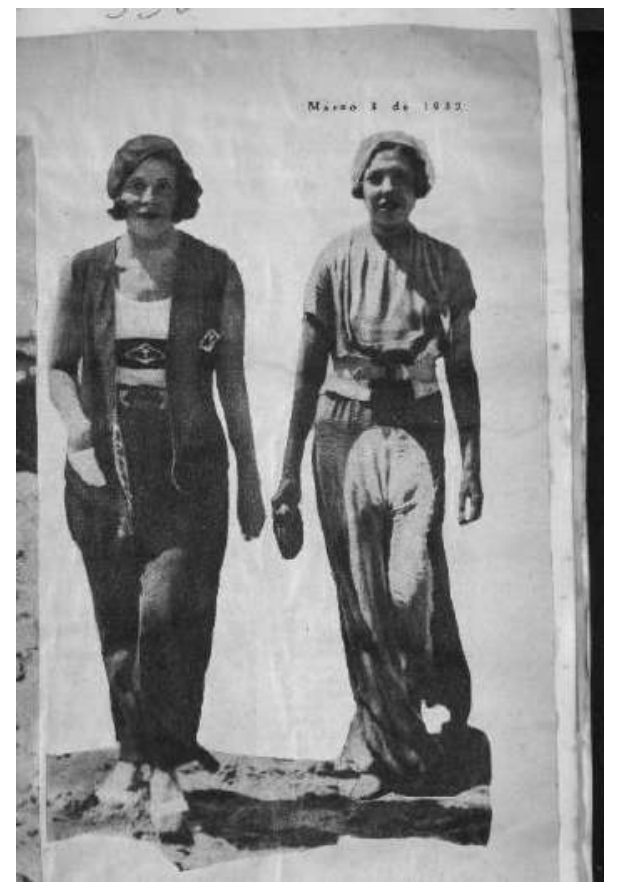

Imagen 5. Libro 4, Foto n. ${ }^{\circ}$ 50, 3 de marzo de 1932. Carmen Senillosa de Campos Catelín con original pijama estilo marinero e Irma Williams con vistoso piyama de sinelik amarillo y blanco. 
Sin embargo, además de modelos, las mujeres casadas aparecen fotografiadas siempre en compañía de sus hijos, en la playa o posando en los jardines al frente a sus esplendidas mansiones. Esto demuestra que estos permanecían en la ciudad con sus madres. En varios casos acompañados por sus niñeras. Esta es la única que desarrolla un trabajo asalariado. Sin embargo, cuando aparecen en las fotografías no se las menciona.

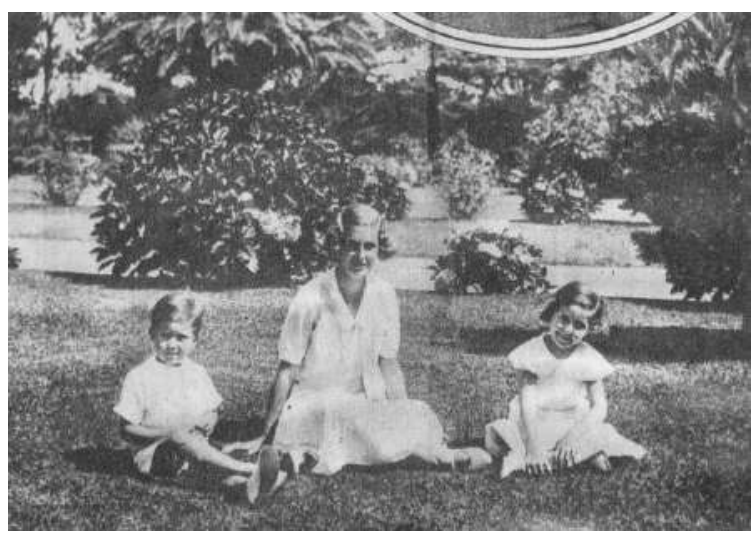

Imagen 6. Libro 4, Foto n. ${ }^{\circ}$ 65, 13 de marzo de 1932. Josefina Agustina Anchorena de Leloir y sus hijos Sara y Alejandro

Imagen 7. Libro 4, Foto n. ${ }^{\circ} 66,13$ de marzo de 1932. Josefina Rodríguez Larreta de Álzaga Unzué y sus hijos Agustina, Angélica e Inés

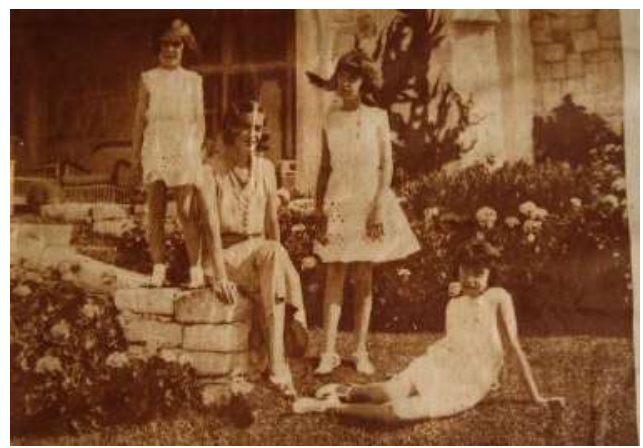

Por último, desde la semiología, es importante mencionar el contrato de lectura subyacente en las páginas del diario La Prensa, que de ninguna manera es casual y ubica en distintos planos de la página a unas y otras. De allí la decisión de indicar en los cuadros de análisis, como una variable, las dimensiones de cada una de las fotografías y la ubicación espacial respectiva, junto a su identificación numérica y su epígrafe. No es lo mismo que una imagen esté en la página izquierda, que a la derecha, o en el ángulo superior derecho o en el inferior izquierdo (Fig. 1 del anexo). Todos estos elementos refuerzan ese signo icónico como un producto cultural, registro de una época determinada, productor de un imaginario, a través de las representaciones que circulan y definen un sistema de creencias apropiadas por la sociedad, y donde se encuentran los caracteres ideológicos que las sustentan y recrean, sin solución de continuidad. 


\section{La representación de habitus}

Desde la sociología, Bourdieu se interesa por la fotografía en su obra Un arte medio (1975). Allí, la define como una práctica social codificada, por lo tanto para él, no es una mímesis ni hay transparencia. La estructura y sintaxis obedecen a cánones implícitos que se imponen como norma general; en consecuencia, al abordarla como objeto de estudio sociológico, para este autor, es necesario en primer término, establecer cómo regula y organiza su práctica individual, cada grupo social, y cómo le confiere funciones que corresponden a sus propios intereses.

Las normas que organizan la captación fotográfica del mundo, según la oposición entre lo fotografiable y lo no fotografiable, son indisociables del sistema de valores implícitos propios de una clase, de una profesión o de un círculo artístico, respecto del cual la estética fotográfica no es más que un aspecto, aun cuando pretenda, desesperadamente la autonomía. Comprender adecuadamente una fotografía no es solamente recuperar las significaciones que proclama, es también descifrar el excedente de significación que revela, en la medida en que participa de la simbólica de una época, de una clase o de un grupo artístico (Bourdieu, 2000: 44).

El sociólogo francés vuelve sobre esta idea en la obra El sentido práctico (1994), donde se propone rescatar la dimensión activa de la práctica y las acciones generadoras de determinados habitus - entendido como posibilidad de invención, pero también como necesidad y limitación-; pero también en La dominación masculina (1998), donde el habitus se traduce en esquemas de percepción, de apreciación y de acción adaptados al orden social impuesto, que reproduce sin más, en este caso, la práctica fotográfica que nos ocupa.

La construcción de las imágenes turísticas de las mujeres de la elite argentina, a principios de la década del treinta en Mar del Plata, produce y reproduce determinados estereotipos a partir de la naturalización de roles de género que instituyen las representaciones características de los contextos hegemónicos. En palabras de Bourdieu, reconocemos una sociodicea masculina que acumula dos operaciones: «legitima una relación de dominación inscribiéndola en una naturaleza biológica, que es en sí misma una construcción social naturalizada» (Bourdieu, 2000: 37).14

En este sentido, las presentaciones escenográficas exhiben los ritos turísticos más reiterados en el balneario argentino. Se constituyen así, en un orden simbólico que alienta la inclusión y pertenencia para otros protagonistas. Paralelamente propone una identidad

${ }^{14}$ Sociodicea: concepto de Bourdieu utilizado para legitimar un orden social determinado. 
femenina para los sectores más encumbrados de la Argentina, a partir de la reiteración de determinados habitus de clase y de género, donde las mujeres reproducen aquellos códigos que le asignan pertenencia y realce social: descanso al aire libre, en la playa, preocupación por la moda, tanto en el vestuario como en el cabello, bailes de disfraces, para las jóvenes casaderas y atención y dedicación a sus hijos, tanto en los juegos en la playa, como al frente de sus mansiones, para las casadas. Se ofrece así un sistema de creencias y prácticas de carácter político imbricado con las relaciones de poder. De manera tautológica, lo producido se encadena a lo esperado y también a lo deseado. El valor de verdad queda así plasmado en las imágenes apropiadas por los lectores. Así, paulatinamente el imaginario social se instituye con características bien claras.

Si bien al organizar el corpus de fotografías, hemos desarrollado una propuesta de clasificación a partir de títulos, temáticas y personas representadas, cuya exposición aquí sería muy tediosa a la lectura, mencionamos la sistematización de los cuarenta y tres títulos de los suplementos que arroja las siguientes categorías: cuarenta tienen que ver con Mar del Plata: diecisiete se refieren a las playas en cada temporada, once a la modernización urbana, en dos casos las dueñas posan frente a sus casas acompañadas de sus hijos y tres ejercitan algún deporte (golf y polo en bicicleta). El resto se reparte entre: la laguna La Brava (una), Ejercicios militares de buzos tácticos en el mar (una), las colonias de vacaciones para hijos de suboficiales del ejército (una) y del Patronato de la Infancia y el Asilo Unzué (tres). El accionar de dos instituciones dedicado a la formación de niñas: San Vicente Paul, de las damas vicentinas y el asilo Unzué, a cargo de la Sociedad de Beneficencia (tres) y sobre el Día del Pescador (una). Estas últimas dedicadas a otros sectores sociales, refieren a las vacaciones de los niños de estas instituciones en la ciudad, en general durante en el último mes de marzo. Mencionamos, por último, tres suplementos uno sobre la exposición internacional de Sevilla, y dos sobre las atracciones turísticas de las provincias de San Juan y a Jujuy respectivamente.

Desde un plano sociológico, nos interesa reconocer la construcción de un imaginario de las representaciones que impone una definición diferenciada para los cuerpos femeninos. Las divisiones constitutivas del orden social, con mayor exactitud, las relaciones sociales de dominación, que muestran hábitos diferentes. La representación se ve investida objetivamente de un sentido común, entendido como consenso práctico. Las fotografías del diario La Prensa exponen así, un sociograma como una máquina simbólica que ratifica los roles y divisiones entre los sexos. El espacio del ocio turístico es más 
adecuado para las mujeres, quienes, además de exponer visualmente su belleza y su integración plena al orden social instituido, se descubren a sí mismas en un círculo de distinción, de encuentro, de reconocimiento social, en el selecto escenario turístico creado por ellos y para ellos. El único suplemento que refleja una mayoritaria presencia masculina está ligado al titular: Ejercicios militares de buzos tácticos en el mar, donde se destaca un trabajo de esfuerzo físico y racionalidad.

Por otra parte, la presencia de otros sectores está representada en La Prensa con relación a esas mujeres que participaban en forma activida en acciones de protección caritativa, pero desde una composición absolutamente diferente. En las fotografías del Día del Pescador, en el puerto, las del Patronato de la Infancia o las del Asilo Unzué, esos otros sectores están agrupados. No hay individualización posible, y si la hubiera al focalizar un rostro, por ejemplo, el epígrafe que acompaña no hace referencia particular a este; sin embargo, el madrinazgo benéfico, de las damas que escolta aquellas actividades, sí es distinguido con el nombre y apellido de cada una de las mujeres que participa. Ellas cruzaban el puente que relacionaba ambos sectores. Desde la construcción del imaginario histórico social, se naturalizaba un orden general sin fisuras, que colocaba a cada cual en un espacio claramente diferenciado. La composición y selección de las imágenes son muy elocuentes al respecto. Los epígrafes que acompañan las fotos lo refuerzan. No hay individualización. Se resalta la institución que alberga a los niños y permite por ejemplo el acceso a los baños de mar para ellos (Fig. 2).

El título del 12 de febrero de 1933: «El Asilo Saturnino Unzué de Mar del Plata Vista general del edificio que ocupa el Asilo Saturnino Unzué en Mar del Plata, donado por las señoras María Unzué de Alvear y Concepción Unzué de Casares» alude a las donantes con nombre y apellido, mientras que las imágenes que hacen referencia a las asiladas como «El refectorio del asilo en la hora del almuerzo. Vista general de la sala de costura», etc. detallan los espacios de acogida a las niñas reforzando la destacada tarea que aquellas damas realizan hacia la infancia desamparada; o como en el caso del Patronato de la Infancia, un conjunto anónimo de niños vestidos iguales y todos abigarrados entre sí. Si comparamos unas y otras imágenes, vemos que mientras que en las damas hay una definición nominada, a partir de la reiteración de poses, de espacio geográficos - la playa, las mansiones con sus áreas abiertas y despejadas- en las otras, hay madejas de rostros indefinidos, oscuros e imprecisos. Sin dudas, ambos escenarios se enfrentaban, y el conflicto dramático entre ellos fluye con claridad. 


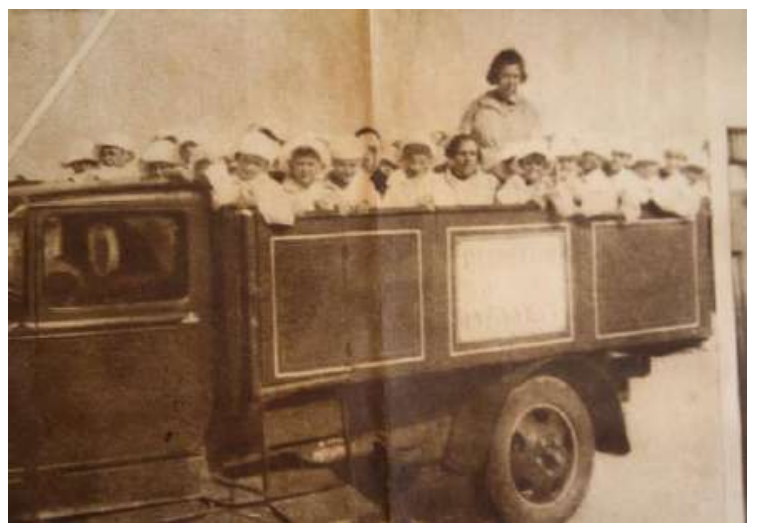

Imagen 8. Libro 5 , Foto n. $^{\circ} 94,5$ de febrero de 1933. Patronato de la Infancia. Grupo de niños en el camión en el que son conducidos a la playa.

Imagen 9. Libro 5, Foto ${ }^{\circ}{ }^{\circ}$ 95, 12 de febrero de 1933. El Patronato de la Infancia Durante el baño de mar

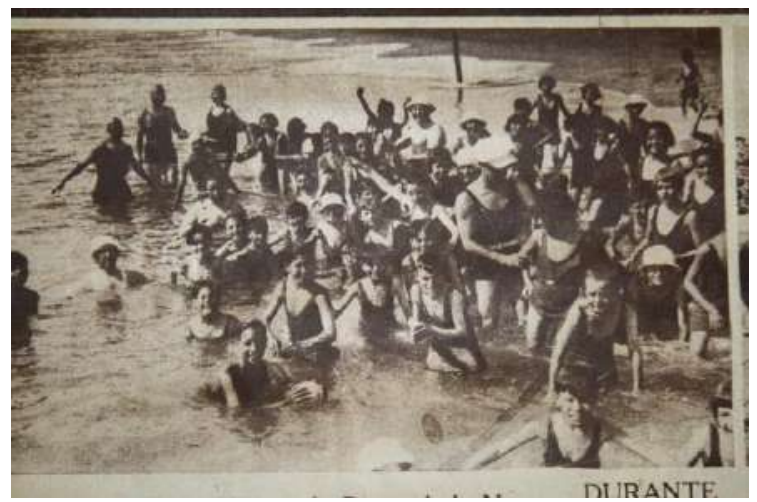

\section{La construcción de las imágenes tiene una historia}

Al deconstruir el entramado, observamos que el buen sentido organiza el habitus de clase que nutre el magma de significaciones naturalizadas que conocemos como imaginario social. Desde las fotografías que el diario La Prensa presentaba a sus lectores, proponía el deber ser, y los exhortaba a formar parte de sus representaciones. Por su parte, la sintaxis prefiguraba determinados enunciados comunicativos. Vemos que la composición está orientada a destacar a las mujeres o a los niños con nombre propio, a partir de la forma vertical para reforzar el individualismo. Cuando se busca acentuar el marco de la playa, por ejemplo, se reiteran las estructuras apaisadas con una línea del horizonte más alta de la media de la composición. Esto destaca, por repetición, la arena, el mar o los parques y las estructuras de las mansiones. Desde la reiteración dan forma a lo real, a lo normal, a lo cotidiano, a través de lo cual conforman una imagen armoniosa, placentera a la mirada. Cruzada por una iluminación que es, en general cenital, o sea de arriba abajo. 
La apropiación de sentidos sobre la trascendencia y distinción social es promovida a través de la repetición. Así, sin interrupción, cada una de las fotografías de La Prensa exhibe una presencia femenina jerarquizada y distinguida con determinadas características. Sin embargo, cuantitativamente lo que prevalece es un control visual sobre las actividades de estas mujeres. Estaban en Mar del Plata, en espacios abiertos, con sus hijos, en la playa, con los atuendos de moda, proponiendo a sus pares un deber ser determinado. El ojo de la cámara, que en general era masculino, fijaba así un contexto de presentación sugiriendo un instante casual, que sin embargo, a través de la cámara, quedaba congelado.

Consecuentemente, sostenemos desde una mirada crítica que la fotografía de prensa es una herramienta invalorable para el reconocimiento del imaginario social de una época - desde la semiología y la sociología - que deshilvana la iconicidad de lo observado, y destaca el carácter construido de las imágenes. La lectura que propone a sus lectores el diario referido, en estos años, expone un mandato ético-político para las mujeres de la élite: su responsabilidad como cuidadoras de sus hijos y garantes de la continuidad de un sistema de acción social ligada a la beneficencia, no como una tarea rentada, como una política pública de Estado, sino como una virtud caritativa hacia los más débiles socialmente. El privilegio de pertenecer y gozar de una identidad que merecía ser distinguida, mirada e imitada, solo se circunscribía a un sector. La elite a través de la fotografía asumía las desigualdades. Esa capacidad para disfrutar y experimentar placer les pertenecía y era de orden natural. Los otros todavía deberían esperar un poco más de una década, cuando este medio gráfico fuera intervenido por el gobierno, peronista, y la estética visual diera un giro sustancial a través de otros soportes.

\section{Anexo metodológico \\ Muestra de las fichas de análisis de las fotografías}

Libro 4, 13 de marzo de 1932. En Mar del Plata (nueve fotografías)

\begin{tabular}{|l|l|l|l|}
\hline N.o & Dimensiones & Posición & Epígrafe \\
\hline $\mathbf{5 9}$ & $18 \times 14 \mathrm{~cm}$ & Superior izquierda & $\begin{array}{l}\text { Adela Leloir de Rodríguez Larreta } \\
\text { y su hijo Augusto }\end{array}$ \\
\hline $\mathbf{6 0}$ & $19 \times 15 \mathrm{~cm}$ & Superior derecho & $\begin{array}{l}\text { Agustina Rodríguez Larreta de } \\
\text { Alzaga Unzué y sus hijas } \\
\text { Agustina, Angélica e Inés }\end{array}$ \\
\hline
\end{tabular}




\begin{tabular}{|l|l|l|l|}
\hline $\mathbf{6 1}$ & $15 \times 10 \mathrm{~cm}$ & Medio izquierda & $\begin{array}{l}\text { Josefina Älzaga Unzué de } \\
\text { Sánchez Elia y su hija Josefina }\end{array}$ \\
\hline $\mathbf{6 2}$ & $\begin{array}{l}13 \times 9 \mathrm{~cm} . \text { Forma } \\
\text { oval }\end{array}$ & Medio superior & $\begin{array}{l}\text { María Teresa Devoto de Ortíz } \\
\text { Basualdo y su hijita María Teresa }\end{array}$ \\
\hline $\mathbf{6 3}$ & $18 \times 15 \mathrm{~cm}$ & Medio superior derecho & $\begin{array}{l}\text { Clara Uribelarrea de White y sus } \\
\text { hijos: Clara, Francisco y Martha }\end{array}$ \\
\hline $\mathbf{6 4}$ & $10 \mathrm{~cm}$ de diámetro & Media inferior. & $\begin{array}{l}\text { Martha Bosch Alvear de Estrada y } \\
\text { su hijita Marta }\end{array}$ \\
\hline $\mathbf{6 5}$ & $15 \times 11 \mathrm{~cm}$ & Inferior izquierda. & $\begin{array}{l}\text { Inés Ayerza de Magnanini y sus } \\
\text { hijos: Luis, Inés y Fernando }\end{array}$ \\
\hline $\mathbf{6 6}$ & $13 \times 9 \mathrm{~cm}$ & Medio inferior & $\begin{array}{l}\text { Sara Josefina Anchorena de } \\
\text { Leloir y sus hijos Sara y Alejandro }\end{array}$ \\
\hline $\mathbf{6 7}$ & $14 \times 12 \mathrm{~cm}$ & Inferior derecho & $\begin{array}{l}\text { Sofía Cranwell de Demarchi y sus } \\
\text { hijos Sofía y Clara }\end{array}$ \\
\hline
\end{tabular}

Fig. 1: ejemplo de ficha de análisis con epígrafes que destacan a las mujeres con nombre y

apellido

Libro 4, 23 de febrero de 1933. El veraneo en Mar del Plata de los niños asilados en el patronato de la infancia (diez fotografías)

\begin{tabular}{|l|l|l|l|}
\hline No & Dimensiones & Posición & Epígrafe \\
\hline $\mathbf{8 6}$ & $21 \times 17 \mathrm{~cm}$ & Superior izquierdo & $\begin{array}{l}\text { Niños reunidos con la directora } \\
\text { del establecimiento }\end{array}$ \\
\hline $\mathbf{8 7}$ & $18 \times 7 \mathrm{~cm}$ & Superior derecho & $\begin{array}{l}\text { Frente de los tres cuerpos del } \\
\text { edificio con que cuenta el } \\
\text { patronato de la infancia en Mar } \\
\text { del Plata }\end{array}$ \\
\hline $\mathbf{8 8}$ & $10 \times 7 \mathrm{~cm}$ & $\begin{array}{l}\text { Medio superior } \\
\text { izquierdo }\end{array}$ & Sin epígrafe \\
\hline $\mathbf{8 9}$ & $15 \times 10 \mathrm{~cm}$ & Medio superior & Sin epígrafe \\
\hline $\mathbf{9 0}$ & $13 \times 10 \mathrm{~cm}$ & $\begin{array}{l}\text { Medio superior } \\
\text { derecho }\end{array}$ & $\begin{array}{l}\text { En el comedor } \\
\text { 91 }\end{array}$ \\
\hline $\mathbf{9 2}$ & $23 \times 14 \mathrm{~cm}$ & $\begin{array}{l}\text { Medio inferior } \\
\text { derecho }\end{array}$ & $\begin{array}{l}\text { Una de las galerías laterales que } \\
\text { están rodeadas de jardines }\end{array}$ \\
\hline $\mathbf{9 3}$ & $11 \times 7 \mathrm{~cm}$ & Inferior izquierdo & Durante el baño de mar \\
\hline $\mathbf{9 4}$ & $14 \times 11 \mathrm{~cm}$ & Medio inferior & $\begin{array}{l}\text { Grupo de niños en el camión en } \\
\text { el que son conducidos a la playa }\end{array}$ \\
\hline $\mathbf{9 5}$ & $12 \times 10 \mathrm{~cm}$ & Inferior derecho & El refectorio del establecimiento \\
\hline
\end{tabular}

Fig. 2. Ejemplo de ficha de análisis que refieren a otros grupos sociales 


\section{Obras citadas}

\subsection{Bibliografía}

Agudello, Pedro Antonio, (Des)hilvanar el sentido/los juegos de Penélope. Una revisión del concepto de imaginario y sus implicaciones sociales. En: UniPluri/versidad, Vol. 11, N. ${ }^{\circ}$ 3, Medellín: Facultad de Educación, Universidad de Antioquía, 2011

Amar, Pierre-Jean, El fotoperiodismo, Buenos Aires: La marca, 2005.

Arfuch, Leonor, Devalle, Verónica, Visualidades sin fin. Imagen y diseño en la sociedad global, Buenos Aires: Prometeo, 2009.

Barthes, Roland, La cámara lúcida, Buenos Aires: Paidós, Comunicación, 2004.

- Mitologías, Buenos Aires: Siglo Veintiuno Editores, 2005.

- Lo obvio y lo obtuso, Imágenes, gestos y voces, Buenos Aires: Paidós, 2009.

Belting, Hans, Antropología de la imagen, Buenos Aires: Katz, 2007.

Benjamin, Walter, «La máquina en la época de su reproductibilidad técnica». En: Discursos interrumpidos I, Madrid: Taurus, 1989.

Bourdieu, Pierre, La dominación masculina, Barcelona: Anagrama, 2000

- Un arte medio, Barcelona: G. Gili, 2003.

Costoriadis, Cornelius, La institución imaginaria de la sociedad, Buenos Aires: Tusquets, 1993.

Fiorini, Daniela, Schilman, Leticia, «Apuntes sobre el sentido de la imagen», en: Arfuch, Leonor, Devalle, Verónica, Visualidades sin fin, Imagen y diseño en la sociedad global, Buenos Aires: Prometeo, 2009.

Malosetti Costa, Laura Gené, Marcela, Impresiones porteñas, Buenos Aires: Edhasa, 2009.

Mirzoeff, Nicholas, Una introducción a la cultura visual, Barcelona: Paidós, 2003.

Montevedre, Mercedes, Fotografías de Mar del Plata (1874-1950), Mar del Plata: Ícono Ideas, 2015.

Pastoriza, Elisa, Un mar de memorias, Buenos Aires: Edhasa, 2009.

- La conquista de las vacaciones. Breve historia del turismo en la Argentina, Buenos Aires: Edhasa, 2011.

Pastoriza, Elisa, «Notas sobre el veraneo marplatense en los albores del siglo Xx: un capítulo indeclinable de la alta sociedad porteña», en: Cacopardo, Fernando (ed.), Apuestas entre dos horizontes. Mar del Plata, ciudad e historia, Buenos Aires: Alianza, 1996.

Pons, Anaclet, Serna, Justo, La historia cultural, Autores, Obras, Lugares, Madrid: Akal, 2013.

Walter, John, Chaplin, Sara, Una introducción a la cultura visual, Barcelona: Octaedro, 2002 
Wechsler, Diana, «Impactos y matices de una modernidad en los márgenes», en: Burucúa, Emilio, Nueva Historia Argentina. Arte, sociedad y política, Buenos Aires: Sudamericana, 1999.

Warley, Jorge, ¿Qué es la semiología?, didáctica de los signos y los discursos sociales, Buenos Aires: Biblos, 2011

Zuppa, Graciela, Bajo otros soles. Miradas a través de folletos, postales, avisos publicitarios y fotografías, Mar del Plata: Eudem, 2012. 